\title{
How Critical Are Critical Care Pharmacists?
}

\author{
Clarence Chant
}

$\mathrm{T}$

he beginnings of caring for critically ill patients date back

to Florence Nightingale's work during the Crimean War in $1854,{ }^{1}$ but the subspecialty of critical care medicine is relatively young. The first US multidisciplinary intensive care unit (ICU) was established in 1958, and the American Board of Medical Subspecialties first recognized the subspecialty of critical care medicine in $1986 .{ }^{2}$ Critical care pharmacy services began around the $1970 \mathrm{~s},{ }^{3}$ growing in the intervening 40 years to become one of the largest practice areas for clinical pharmacists, with its own section in the Society of Critical Care Medicine (SCCM), the largest international professional organization in the field. ${ }^{3}$

The value of critical care pharmacists has been well documented. ${ }^{4}$ Various studies have shown that critical care pharmacists reduce medication errors, improve patient outcomes, reduce costs and waste, and decrease mortality rates among patients with thromboembolic diseases or infections. ${ }^{4-6}$ Critical care pharmacists are also recognized as essential by those outside the pharmacy profession, including the SCCM. In fact, several SCCM guidelines describe the scope of pharmacy practice and pharmacists' role within best practice models for ICU staffing. ${ }^{7.8}$ One leader of the patient safety movement, Dr Peter Pronovost, has stated that the presence of critical care pharmacists is 1 of 6 ICU characteristics that would improve patient outcomes.

Two articles in this issue of the CJHP add to the growing body of literature demonstrating the diverse roles of critical care pharmacists. In an investigation of the frequency and types of errors associated with administration of IV medications in the ICU, Summa-Sorgini and colleagues ${ }^{10}$ found an error rate of $14.3 \%$ or 3.0 errors per infusion. This study highlights the potential role of critical care pharmacists in quality improvement, detection of errors, and production of scholarly work. Walker and others ${ }^{11}$ describe in detail the establishment of an antimicrobial stewardship team in the ICU and how the team's work complements current efforts of critical care pharmacists in monitoring antimicrobial therapy of ICU patients.

It would therefore appear that critical care pharmacists should be a basic requirement for any ICU, because they are

involved in diverse aspects of care and scholarly activities related to critically ill patients, because they are well accepted by their peers, and because their work is associated with improved clinical, economic, and humanistic outcomes. ${ }^{4}$ However, in a 2006 survey in the United States, completed by 382 hospitals with a total of 1034 ICUs, only $62.2 \%$ of respondents reported having dedicated ICU pharmacists (full- or parttime), ${ }^{12}$ with these pharmacists attending patient care rounds for an average of 4.4 days/week. Fewer than half $(41 \%)$ of the hospitals reported that pharmacists provided therapeutic advice to physicians beyond the usual daytime service hours, and only $18.2 \%$ of respondents had ICU pharmacy satellite services $24 \mathrm{~h} /$ day. These results are consistent with an international survey conducted by LeBlanc and others, ${ }^{13}$ who reported that $74.4 \%$ of 134 non-US critical care pharmacists attended medical rounds.

So why is a service with demonstrated benefits absent from so many hospitals? Furthermore, for those hospitals that do have dedicated critical care pharmacists, why are they present for only part of the day, while other ICU team members are present 24/7? Are critical care pharmacists "critical" only some of time? The concept of having critical care pharmacy services available $24 / 7$ is certainly not new. ${ }^{14}$ The reasons why pharmacists are not present all the time are multifactorial and may include lack of financial resources, lack of adequately trained personnel, inconsistent documentation of pharmacists' activities in medical records, lack of a shared practice model, and perhaps (however counterintuitive) the belief of both hospital and pharmacy administrators that critical care pharmacists are not really essential or that they are simply an extension of the product (i.e., medications), rather than being closely linked to the patient. This is contrary to the fact that an SCCM task force report defining the best practice model for an ICU ranked the evidence 
supporting the benefits of critical care pharmacists highest (level C), above the evidence for other health care professionals. ${ }^{8}$ Just like the "care gap" that exists for patients who are not receiving evidence-based therapies that would improve their outcomes, closure of this "pharmacist gap" will require a joint effort involving not only the profession, but also other stakeholders. Although certain of the factors, such as a lack of financial resources, may be beyond the control of the pharmacy profession, other factors, such as increased documentation in patient records and increased scholarly work demonstrating pharmacists' contributions (including those in this issue of the Journal), can and should be addressed more consistently by all critical care pharmacists. It is only through these efforts that we will achieve the vision of Professor Joseph Dasta, one of the pioneering critical care pharmacists, who described the future of critical care pharmacists as one where "the roles and responsibilities of the pharmacist will expand to include ensuring the accuracy and applicability of clinical, economic, and pharmacogenetic drug information contained in integrated information systems ... [and] the phrase 'clinical pharmacist' will be replaced by 'ICU pharmacotherapy knowledge manager'. The pharmacist will be reimbursed for these services in a manner similar to that used for physicians and nurses." ${ }^{3}$ Let's make critical care pharmacists "critical", all of the time!

\section{References}

1. Grenvik A, Pinsky MR. Evolution of the intensive care unit as a clinical center and critical care medicine as a discipline. Crit Care Clin 2009;25(1): 239-250.

2. History of critical care. Mount Prospect (IL): Society of Critical Care Medicine; 2001-2011 [cited 2011 Nov 3]. Available from: www.sccm.org/AboutSCCM/History_of_Critical_Care/Pages/default.aspx

3. Dasta J. Critical care. Ann Pharmacother 2006;40(4):736-737.

4. Kane SL, Weber RJ, Dasta JF. The impact of critical care pharmacists on enhancing patient outcomes. Intensive Care Med 2003;29(5):691-698.

5. MacLaren R, Bond CA. Effects of pharmacist participation in intensive care units on clinical and economic outcomes of critically ill patients with thromboembolic or infarction-related events. Pharmacotherapy 2009; 29(7):761-768.

6. MacLaren R, Bond CA, Martin SJ, Fike D. Clinical and economic outcomes of involving pharmacists in the direct care of critically ill patients with infections. Crit Care Med 2008;36(12):3184-3189.
7. Rudis MI, Brandl KM; Society of Critical Care Medicine and American College of Clinical Pharmacy Task Force on Critical Care Pharmacy Services. Position paper on critical care pharmacy services. Crit Care Med 2000;28(11):3746-3750.

8. Brilli RJ, Spevetz A, Branson RD, Campbell GM, Cohen H, Dasta JF, et al.; American College of Critical Care Medicine Task Force on Models of Critical Care Delivery. Critical care delivery in the intensive care unit: defining clinical roles and the best practice model. Crit Care Med 2001;29(10):2007-2019.

9. Randolph AG, Pronovost P. Reorganizing the delivery of intensive care could improve efficiency and save lives. J Eval Clin Pract 2002;8:1-8.

10. Summa-Sorgini C, Fernandes V, Lubchansky S, Mehta S, Hallett D, Bailie T, et al. Errors associated with IV infusions in critical care. Can J Hosp Pharm 2012;65(1):19-26.

11. Elligsen M, Walker SAN, Simar A, Daneman N. Prospective audit and feedback of antimicrobial stewardship in critical care: program implementation, experience, and challenges. Can J Hosp Pharm 2012; 65(1):31-36.

12. Maclaren R, Devlin JW, Martin SJ, Dasta JF, Rudis MI, Bond CA. Critical care pharmacy services in United States hospitals. Ann Pharmacother 2006;40(4):612-618.

13. LeBlanc JM, Seoane-Vazquez EC, Arbo TC, Dasta JF. International critical care hospital pharmacist activities. Intensive Care Med 2008; 34(3):538-542.

14. Hall K, Guay M. The implementation of comprehensive critical care pharmacy services through the development of a 24-hour satellite pharmacy. Can J Hosp Pharm 1982;35(6):184-188.

Clarence Chant, PharmD, BCPS, FCSHP, FCCP, is Clinical Pharmacy Specialist/Leader at St Michael's Hospital, Toronto, Ontario. He is also an Associate Editor with the CJHP.

Address correspondence to:

Dr Clarence Chant

Pharmacy

St Michael's Hospital

30 Bond Street, Room Q4036

Toronto ON M5B 1W8

e-mail: CHANTC@smh.ca

\section{Acknowledgements}

The author wishes to acknowledge presubmission review of this editorial by Professor Joseph Dasta.

\section{ON THE FRONT COVER}

\section{Near Thurso, Quebec}

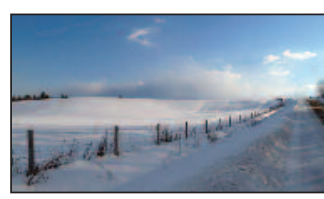

This picture was taken during a drive along the country roads near Thurso, Quebec, on the afternoon of a crisp winter day. Interesting shadows were created by the vegetation and the undulating land. The image was captured by Caroline Cheng, a hospital pharmacist who works in Ottawa, using a Panasonic Lumix DMC-ZS5 camera.

The CJHP would be pleased to consider photographs featuring Canadian scenery taken by CSHP members for use on the front cover of the journal. If you would like to submit a photograph, please send an electronic copy (minimum resolution $300 \mathrm{dpi}$ ) to Colleen Drake at cdrake@cshp.ca. 